\title{
Salt tolerance's toll: prolonged exposure to saline water inflicts damage to the blood cells of dice snakes (Natrix tessellata)
}

\author{
Vanya Koleva $^{1}$, Yurii Kornilev ${ }^{2,3}$, Ivan Telenchev ${ }^{4}$, Simeon Lukanov ${ }^{5}$, Berna Hristova ${ }^{6}$, and \\ Nikolay Natchev ${ }^{1,3}$ \\ ${ }^{1}$ Department of Biology, Faculty of Natural Science, Shumen University, \\ 115, Universitetska St, 9700 Shumen, Bulgaria \\ ${ }^{2}$ National Museum of Natural History, Sofia, 1 Tsar Osvoboditel Blvd., 1000 Sofia, Bulgaria \\ ${ }^{3}$ Department of Integrative Zoology, Faculty of Life Sciences, University of Vienna, \\ Althanstraße, 1090 Vienna, Austria \\ ${ }^{4}$ Department of Ecology and Environmental Protection, Faculty of Biology, Sofia University, \\ 9 Dragan Tzankov Blvd., 1000 Sofia, Bulgaria \\ ${ }^{5}$ Institute of Biodiversity and Ecosystem Research, Bulgarian Academy of Sciences, \\ Blvd. Tzar Osvoboditel 1, 1000 Sofia, Bulgaria \\ ${ }^{6}$ Department of Organic Chemistry and Technology, Faculty of Natural Science, \\ Shumen University, 115, Universitetska St, 9700 Shumen, Bulgaria
}

Correspondence to: Nikolay Natchev (nikolay.natchev@ univie.ac.at)

Received: 21 July 2016 - Revised: 28 December 2016 - Accepted: 3 January 2017 - Published: 24 January 2017

Abstract. Dice snakes (Natrix tessellata, Laurenti, 1768) inhabit oligohaline and brackish waters along the Bulgarian Black Sea coast, where they often forage at sea. Under these conditions, this species should tolerate highly variable blood plasma sodium concentrations for extended time periods, but the effect of high sodium concentrations to blood cell morphology and physiology is largely unknown. In this experiment, we placed adult dice snakes in waters with different salinity for $84 \mathrm{~h}$, representing the three typical saline concentrations in which dice snakes live and forage: $0.2 \% \circ \mathrm{NaCl}$, fresh water, $16 \% \circ \mathrm{NaCl}$, Black Sea water and $36 \% \circ \mathrm{NaCl}$, World Ocean water. We collected blood through cardiocentesis after exposure to each treatment and used Giemsa's solution for staining the formed elements. We registered numerous nuclear abnormalities (nuclear buds, lobes and blebs) in the blood cells of all investigated specimens. In the snakes placed in the waters with high saline concentration $(16$ and $36 \% \mathrm{NaCl})$ we found numerous cells with ruptured membranes. These snakes also showed increased mitochondrial activity compared to those in fresh water (1.85 and 2.53 times higher, respectively). Our data suggest that even though dice snakes show a remarkable tolerance to waters with increased salinity, prolonged exposure to it induces significant physiological stress in $N$. tessellata, which poses a clear limit for their ability to stay in the sea for a long time. 


\section{Introduction}

Aquatic environments play a vital role in the sustainable functioning of ecosystems (Walia et al., 2013). Elevated concentrations of salt in water is a recognized issue for the conservation of aquatic habitats (Crowther and Hynes, 1977; Dickman and Gochnauer, 1978; Martem'yanov, 1989; Howard and Haynes, 1993; Kjensmo, 1997; Williams et al., 2000). Some amphibians and cold-blooded amniotes can tolerate increased water salinity and some even reproduce in brackish water and seawater (Neill, 1958; Chakko, 1968; Christman, 1974; Dunson, 1977; Sillero and Ribeiro, 2010; Natchev et al., 2011). However, the effects of increased water conductivity on the populations of aquatic ectothermic tetrapods are not fully understood (Bentley and SchmidtNielsen, 1971; Spotila and Berman, 1976; Shoemaker et al., 1992; Gomez-Meste et al., 2004; Karraker, 2007; OrtizSantaliestra et al., 2010).

Some snake species live and reproduce in near-brackish and euryhaline waters (Neill, 1958), but the information concerning the extent of their water salinity tolerance is somewhat limited. Dice snakes (Natrix tessellata) are semiaquatic natricines, widely spread in the Palearctic and fish foragers in waters ranging from fresh to saline. According to Ahmadzadeh et al. (2011), N. tessellata in southeastern Iran thrives in waters with salinity between 1.3 and $28 \%$. Brischoux and Kornilev (2014) demonstrated that free-ranging $N$. tessellata from a coastal population in Bulgaria display highly variable plasma sodium concentrations ranging from normonatremia to hypernatremia without any apparent effect on several physiological and behavioural traits (e.g. hematocrit, body condition, foraging). Those snakes inhabit the Black Sea coast and regularly hunt at sea (Naumov et al., 2011; Stojanov et al., 2011; Brischoux and Kornilev, 2014). However, the physiological mechanisms responsible for this tolerance are poorly known. Consequently, the main aim of the present study is to provide assessment of the effects of osmotic changes on the morphology and the mitochondrial activity of the blood cells in N. tessellata. We expect that both the morphology of the formed elements, as well as the mitochondrial activity, will be affected in dehydrated snakes.

\section{Material and methods}

\subsection{Study animals}

We used nine Natrix tessellata (snout-vent length, SVL: $66.5-75 \mathrm{~cm}$; body mass: $124-180 \mathrm{~g}$ ). We sampled only large adult individuals to avoid potential detrimental effects of the procedure on smaller individuals. Since females of this species are significantly larger than the males, only females were included for this preliminary study. Consequently, interpretation of results will be restricted to female individuals of this species. The snakes were collected from the south- ern Bulgarian Black Sea coast, around Poda, a protected site (PS) (42.445706 N, 27.462928 E, Datum: WGS84) and the neighbouring Foros Bay and Mandra Lake (map in Brischoux and Kornilev, 2014). The site $\left(\sim 1.5 \mathrm{~km}^{2}\right)$ encompasses shallow (0-2 $\mathrm{m})$ aquatic habitats, widely ranging in salinity from fresh $(<0.5 \%$ ) and brackish $(0.5-30 \%$ ) to saline water $(>30 \%$ o). Snakes were captured by hand in June-July and were housed in individual plastic containers $48(\mathrm{~L}) \times 36(\mathrm{~W}) \times 24(\mathrm{H}) \mathrm{cm}$ with ample ventilation and water ad libitum. After the termination of the study, the snakes were allowed to return to normonatremia and were released at their capture locations.

\subsection{Treatment}

Initially, all snakes were kept in fresh water for $72 \mathrm{~h}$ to establish normonatremia (Yurii Kornilev and Nikolay Natchev, personal observation, 2015). Then, each animal was randomly assigned to one of three experimental groups and exposed to $0.2 \%$ o NaCl (fresh water), $16 \%$ NaCl (Black Sea water) or $36 \% \mathrm{NaCl}$ (World Ocean water) for $84 \mathrm{~h}$. Water of the respective salinity was added to each container $(48 \times 36 \times 24 \mathrm{~cm})$, reaching depths of about $3-4 \mathrm{~cm}$ in order to expose snakes to the different salinities. Every single specimen was housed in a separate container. A small clay island $(2 \times 8 \times 8 \mathrm{~cm})$ was also provided for snakes to be able to rest without drowning, while always maintaining sufficient contact with the water.

Waters were prepared by adding solid $\mathrm{NaCl}$ to freshwater; the $\mathrm{NaCl}$ was obtained from the Black Sea at a salt extraction facility, located $10 \mathrm{~km}$ from Poda PS. Salinity was measured using a calibrated, hand-held, real-time conductivity measuring instrument (Testo 240, Testo AG). After the treatment, the snakes were moved in containers with fresh water for the period of $10 \mathrm{~min}$ prior to blood sampling.

\subsection{Blood collection}

Blood samples of $0.3-0.4 \mathrm{~mL}$ were obtained by cardiocentesis using a heparinized 30 G-needle and syringe (see Brischoux and Kornilev, 2014). The collected blood was transferred immediately into heparinized Eppendorf vials. Samples were placed in a cooler with ice and within $1 \mathrm{~h}$ the critical laboratory manipulations were performed.

\subsection{Preparing blood smears}

Ten microlitres of blood were placed onto a clean microscope slide and a smear was created using the bevel-edge slide technique. The slides were air-dried at room temperature and fixed in methanol for $20 \mathrm{~min}$ at $4{ }^{\circ} \mathrm{C}$. Nuclei were stained in a $5 \%$ Giemsa's solution for $45 \mathrm{~min}$. Three blood smears per snake were prepared. 


\subsection{Morphological analysis of the blood cells}

The monolayer cells were analysed under $1000 \times$ oil immersion. Only fields of view with $>15$ erythrocytes clearly isolated from the surrounding cells were counted (see Bell and Gregory, 2014). The assessed erythrocytes per snake were at least 2000. Erythrocytes nucleus with the correct oval shape, or with only a slight deviation from the oval shape was counted as normal nucleus. The following cell morphological changes were analysed: presence of nuclear buds, nuclear blebs, lobed nuclei, notched nuclei, plasma membrane disruptions, cytoplasmic retraction and morphological abnormal shape of the erythrocytes. Normal distribution was verified by the Shapiro-Wilk test and statistically tested using an analysis of variance (ANOVA) with salinity as a grouping variable and percentage of normal nuclei and damaged erythrocytes (erythrocytes with ruptured cell membrane, but still recognizable as a cell unit) as dependent variables (average values of the three replicates from each individual). An least significant difference (LSD) post-hoc test was used to determine differences between treatments.

\subsection{Mitochondrial activity assay}

The assay principle is based upon the reduction of the tetrazolium salt WST-1 (Roche Applied Science) to formazan in the mitochondria of living cells. For each individual sample, $50 \mu \mathrm{L}$ of blood was added to a $450 \mu \mathrm{L}$ complete culture medium (MEM with $10 \%$ PBS, gentamicin and penicillin) and gently suspended. In 96 well flat-bottomed microplates, $100 \mu \mathrm{L}$ well ${ }^{-1}$ of media/blood mixture and $10 \mu \mathrm{L}$ well ${ }^{-1}$ of WST-1 were placed. The microplate was further incubated for $4 \mathrm{~h}$ at $20^{\circ} \mathrm{C}$. The absorbance of formazan product was quantified at $450 \mathrm{~nm}$ using an enzyme-linked immunosorbent assay (ELISA) reader. The assay was carried out in three replicate wells. As in the analysis of the blood cells, the normality of the data was inspected and confirmed by a ShapiroWilk test, followed by ANOVA with salinity as a grouping variable and absorbance as a dependent variable (average values for each individual). An LSD post-hoc test was used to determine differences between treatments.

All statistical tests were performed using the Statistica v.7.0 software (StatSoft, Inc. 2004). The chosen alpha level for statistical significance was $p<0.05$.

\section{Results and discussion}

Various abnormalities in the form of the erythrocyte nuclei are used as effective indicators of the negative influence of the environment on the cells of many aquatic animals (Ateeq et al., 2002; Jiraungkoorskul et al., 2007; Ali et al., 2008; Anbumani and Mohankumar, 2011; Walia et al., 2013; Hayretdağ et al., 2014; Furnus et al., 2014; Asker et al., 2015). The sublingual salt gland is the primary site of salt excretion in sea snakes (Babonis et al., 2009), but dice snakes
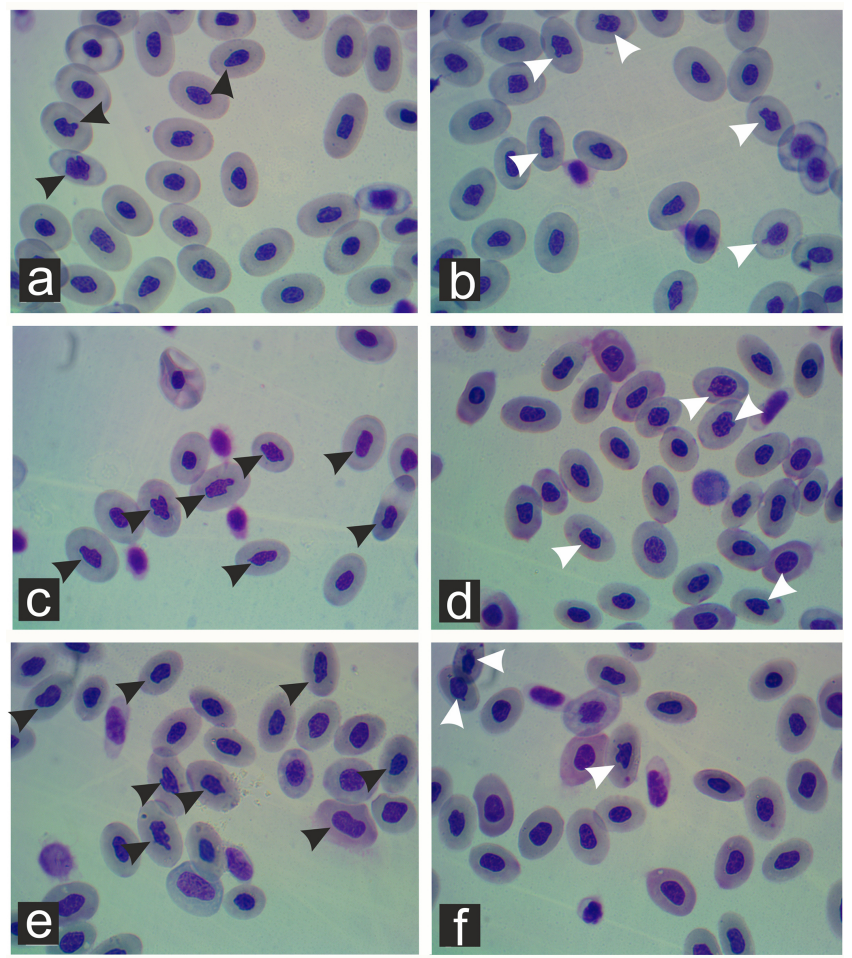

Figure 1. Natrix tessellata: Nuclear buds and lobed nuclei (black arrowheads) from (a) $0.2 \% \circ \mathrm{NaCl}$ (fresh water) treatment, (c) $16 \% \circ \mathrm{NaCl}$ (Black Sea water) treatment and (e) $36 \% \circ \mathrm{NaCl}$ (World Ocean water) treatment. Nuclear blebs (white arrowheads) from (b) $0.2 \% \circ \mathrm{NaCl}$ (fresh water) treatment, (d) $16 \% \circ \mathrm{NaCl}$ (Black Sea water) treatment and (f) $36 \% \mathrm{NaCl}$ (World Ocean water) treatment.

lack salt glands. However, these snakes can spend long periods of time in brackish and saline waters (see Brischoux and Kornilev, 2014). The authors measured hypernatremia up to $195.5 \mathrm{mmol} \mathrm{L}^{-1}$ in some specimens. It could be expected that the morphology of the blood cells would be affected in specimens that spent prolonged periods in water with increased salinity compared to specimens exposed to fresh water.

In our experiments, the presence of lobed and notched nuclei, as well as nuclear buds and blebs, was detected in the blood cells of the snakes from all three treatments, albeit in very different proportions (Fig. 1, Table 1). Erythrocytes nuclei with the correct oval shape or with slight shape deviations were $10.2 \%$ for the control freshwater group, $11.11 \%$ for Black Sea water and $20.21 \%$ for World Ocean water. The ANOVA test revealed marginally significant differences $(F=4.14, \mathrm{~d} f=2, p=0.074)$. Post-hoc tests demonstrated significant differences between fresh and World Ocean water $(p=0.035)$; no statistically significant differences between fresh and Black Sea water $(p=0.616)$ and only marginally significant differences between Black Sea and World Ocean water $(p=0.072)$. 
Table 1. Morphological changes of erythrocyte membranes or erythrocyte nuclei after treatment with waters of different salinities. Values represent the percentage of normal nuclei from all counted nuclei per treatment group, or the percentage of damaged membranes from all counted erythrocytes per treatment group.

\begin{tabular}{rrrr|rr}
\hline \multirow{2}{*}{ Salinity $\begin{array}{r}\text { Analysed erythrocytes } \\
\text { (total number) }\end{array}$} & \multicolumn{2}{c}{ Normal nuclei } & \multicolumn{2}{c}{$\begin{array}{c}\text { Damaged cell } \\
\text { membranes }\end{array}$} \\
\cline { 3 - 6 } & & $\%$ & $n($ mean \pm SD) & $\%$ & $n($ mean \pm SD) \\
\hline $0.2 \% 0$ & 6280 & 10.2 & $640(190 \pm 18.48)^{\mathrm{b}}$ & 0.37 & $23(7.67 \pm 1.15)^{\mathrm{b}}$ \\
$16 \% 0$ & 6374 & 11.11 & $708(236 \pm 72.08)^{\mathrm{a}}$ & 71.16 & $4536(1512 \pm 421.03)^{\mathrm{a}}$ \\
$36 \% 0$ & 6284 & 20.21 & $1270(423 \pm 165.9)^{\mathrm{a}}$ & 45.96 & $2888(963 \pm 413.96)^{\mathrm{a}}$ \\
\hline
\end{tabular}

a, b Different superscript letters indicate significant differences among treatments $(p<0.05)$.

Snakes exposed to 16 and $36 \%$ salinity presented erythrocytes with ruptured and damaged membranes of 71.16 and $45.96 \%$ compared to only $0.37 \%$ in the freshwater control group (Table 1). This difference was statistically significant $-F=14.96, \mathrm{~d} f=2, p=0.005$. The post-hoc test revealed statistically significant differences between the control and both treatments $-16 \% \circ(p=0.002)$ and $36 \% o(p=0.013)$, but not between the two saline treatments $(p=0.096)$. It should be noted that in Table 1 only the number of the erythrocytes which were detectable as a cell unit (with cell membrane) is given. In the sample from the animals treated with $36 \%$ water, we observed large fields with chromatin remains. This indicates that the number of disintegrated erythrocytes might be much higher than counted. Hence, the total percentage of erythrocytes with normal nuclei from the specimens treated with oceanic water might be actually much lower than that of the other two samples. For the three specimens from the $36 \%$ water group, we were only able to count blood cells with intact (or nearly intact) membranes in order to reach the amount of 2000 cells per specimen (see Bell and Gregory, 2014) - a large amount of erythrocytes were destroyed and the cell elements were unrecognizable. This distortion may explain the higher percentage of normal nuclei in the sample of specimens treated with oceanic water compared to the sample of fresh water.

It is possible that the occurrence of most nuclear anomalies from the fresh water group observed in this study is related to the prolonged erythrocyte lifespan, as the average lifespan of these cells in cold-blooded amniotes is 600-800 days (Stacy et al., 2011; Strunjak-Perovic et al., 2010). Therefore, abnormal morphological forms of erythrocyte nuclei are not effective indicators for assessment of the negative influence of environment onto the formed elements of the blood in $N$. tessellata.

The numerous cells with ruptured membranes (Fig. 2), found in blood smears of snakes exposed for a prolonged time to 16 and $36 \%$ salinity, indicate hemolysis and osmotic stress (see Madden et al., 2014). A fundamental challenge for the cell is a change in the osmolarity of the surrounding medium (Pastor et al., 2009). Osmoregulation is a major physiological challenge for numerous vertebrates that are
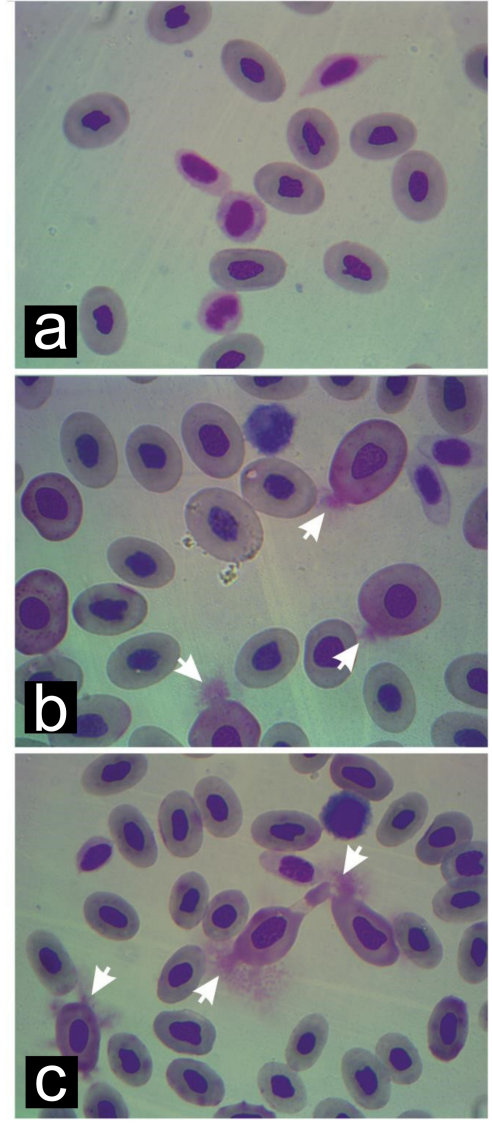

Figure 2. Blood cells of dice snakes after treatment with (a) $0.2 \% \circ \mathrm{NaCl}$ (fresh water), (b) $16 \% \circ \mathrm{NaCl}$ (Black Sea water) and (c) $36 \% \circ \mathrm{NaCl}$ (World Ocean water) for $84 \mathrm{~h}$. White arrowheads indicate the ruptured cell membranes. Note the lack of ruptured cells in the snakes resident in fresh water.

subject to extensive changes in the salinity of their environment (Gutiérrez et al., 2011). Our data suggest that disintegration of the cell membranes was a result of the osmotic pressure gradient following prolonged dwelling in waters with increased conductivity. 


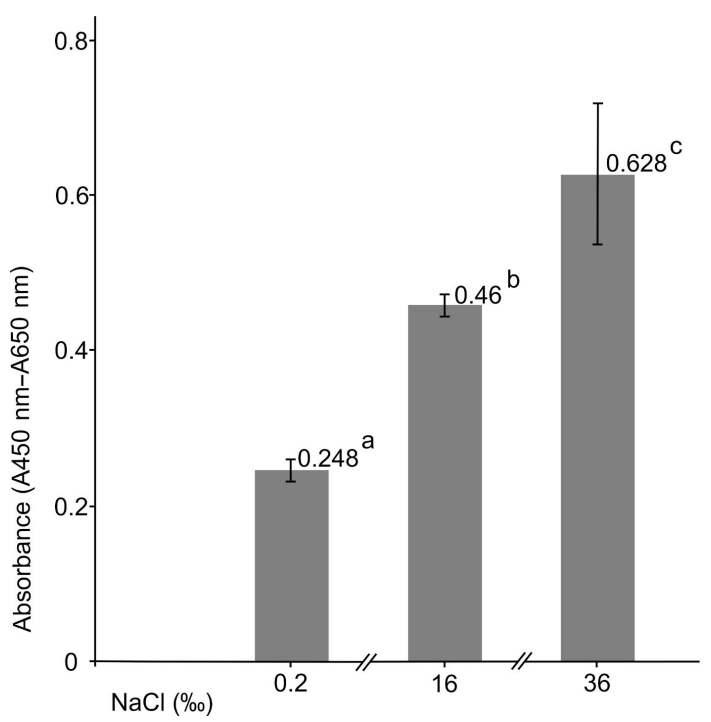

Figure 3. Mitochondrial activity of blood cells (mean \pm SD) in wild-caught animals exposed to $0.2 \% 0 \mathrm{NaCl}$ (fresh water), $16 \%$ NaCl (Black Sea water) and $36 \%$ NaCl (World Ocean water) for $84 \mathrm{~h}$. Different letters indicate significant differences among groups $(p<0.057)$.

The mitochondrial activity of the blood cells was estimated based on the reduction of the tetrazolium compound (WST1) by intracellular dehydrogenases to formazan, released in the culture medium. The mean mitochondrial activities after removing the snakes from solutions of 16 and $36 \%$ o $\mathrm{NaCl}$ increased by 1.85 and 2.53 times compared to those of snakes resident in fresh water (Fig. 3). These differences in absorbance were statistically significant $(F=14.66$, $\mathrm{d} f=2, p=0.005)$, and the post-hoc test revealed that all three groups were significantly different from each other as follows: $\mathrm{a}-\mathrm{b}, p=0.023$; $\mathrm{a}-\mathrm{c}, p=0.002 ; \mathrm{b}-\mathrm{c}, p=0.056$ (see Fig. 3). Pastor et al. (2009) identified the raised mitochondrial function as an important physiological determinant of the efficient adaptive response to osmotic stress. The presence of morphologically damaged cells, the increased mitochondrial activity of the blood cells, as well as the hypernatremia established by Brischoux and Kornilev (2014), is evidence that the prolonged residence in waters with increased conductivity induce physiological stress in $N$. tessellata.

\section{Conclusions}

Our results demonstrate that the presence of abnormal morphological features of the blood cell nuclei cannot be regarded as effective indicators for an assessment of the influence of defined environmental factors in short-term studies in dice snakes. The abnormalities were found in all specimens and may be result of the pre-exposure of some physi$\mathrm{cal} / \mathrm{chemical}$ contaminants from the sampling location - the erythrocyte turnover rate in cold-blooded amniotes is rather slow (see Stacy et al., 2011). The presence of destroyed blood cells and the increased mitochondrial activity detected in two of the snake groups used in our experiments suggest potential change in the osmotic pressure of the blood plasma and impact on the general performance and fitness of the dice snakes.

Author contributions. Vanya Koleva prepared the concept of the study, performed the laboratory manipulations, wrote the manuscript, prepared the images and checked the final versions of the products. Yurii Kornilev aided to the concept of the study, performed the animal handling and manipulations, wrote the manuscript, proofread the manuscript and checked the final version of the products. Ivan Telenchev performed the animal handling and manipulations and checked the final version of the products. Simeon Lukanov wrote the manuscript, performed calculations, proofread the manuscript and checked the final version of the products. Berna Hristova performed the laboratory manipulations and checked the final versions of the products. Nikolay Natchev wrote the manuscript, edited the images, proofread the manuscript and checked the final version of the products.

Competing interests. The authors declare that they have no conflict of interest.

Acknowledgements. This work was partly supported by the Bulgarian National Science Fund (BNSF), Grant No. RD-08266/10.03.2015. Only materials were provided by BNSF and no personal payments were made. All animal experimentation was conducted in accordance with pertinent national statements regarding the care and use of animals (research permit number 520/23.04.2013). We thank François Brischoux for helpful comments on earlier draft of the paper. Daniel Montesinos and two anonymous reviewers provided important remarks on the manuscript.

Edited by: D. Montesinos

Reviewed by: S. Anbumani and one anonymous referee

\section{References}

Ahmadzadeh, F., Mebert, K., Ataei, S., Rezazadeh, E., Gholi, L. A., and Böhme, W.: Ecological and biological comparison of three populations of the Dice snake (Natrix tessellata) from the southern Caspian Sea Coast, Iran, Mertensiella, 18, 388-397, 2011.

Ali, F. K., El-Shehawi, A. M., and Seehy, M. A.: Micronucleus test in fish genome: a sensitive monitor for aquatic pollution, Afr. J. Biotechnol., 7, 606-612, doi:10.5897/AJB2008.000-5020, 2008.

Anbumani, S. and Mohankumar, M. N.: Nuclear and cytoplasmic abnormalities in the fish Catla catla (Hamilton) exposed to chemicals and ionizing radiation, Res. J. Environ. Sci., 5, 867877, doi:10.3923/rjes.2011.867.877, 2011. 
Asker, N., Almroth, B. C., Albertsson, E., Coltellaro, M. J., Bignell, P., Hanson, N., Scarcelli, V., Fagerholm, B., Parkkonen, J., Wijkmark, E., Frenzilli, G., Förlin, L., and Sturve, J.: A gene to organism approach - assessing the impact of environmental pollution in eelpout (Zoarces viviparus) females and larvae, Environ. Toxicol. Chem., 34, 1511-1523, doi:10.1002/etc.2921, 2015.

Ateeq, B., Farah, M. A., Ali, M. N., and Ahmad, W.: Induction of micronuclei and erythrocyte alterations in the catfish Clarias batrachus by 2,4-dichlorophenoxyacetic acid and butachlor, Mutat. Res., 518, 135-144, 2002.

Babonis, L. S., Hyndman, K. A., Lillywhite, H. B., and Evans, D. H.: Immunolocalization of $\mathrm{Na}+/ \mathrm{K}+-$ ATPase and $\mathrm{Na}+/ \mathrm{K}+/ 2 \mathrm{Cl}-$ cotransporter in the tubular epithelia of sea snake salt glands, Comp. Biochem. Physiol. A, 154, 535-540, doi:10.1016/j.cbpa.2009.08.022, 2009.

Bell, K. A. H. and Gregory, P. T.: White blood cells in Northwestern Gartersnakes (Thamnophis ordinoides), Herpetol. Not., 7, 535541, 2014

Bentley, P. J. and Schmidt-Nielsen, K.: Acute effects of sea water on frogs (Rana pipiens), Comp. Biochem. Physiol. A., 40, 547-548, 1971.

Brischoux, F. and Kornilev, Y. V.: Hypernatremia in Dice snakes (Natrix tessellata) from a coastal population: implications for osmoregulation in marine snake prototypes, PLoS ONE, 9, e92617, doi:10.1371/journal.pone.0092617, 2014.

Chakko, G.: Salinity tolerance in some South Indian Anurans, Proc. Indian Acad. Sci. B., 67, 233-236, 1968.

Christman, S. P.: Geographic variation for salt water tolerance in the frog Rana sphenocephala, Copeia, 1974, 773-778, 1974.

Crowther, R. A. and Hynes, H. B. N.: The effect of road de-icing salt on the drift of river benthos, Environ. Pollut., 14, 113-126, 1977.

Dickman, M. D. and Gochnauer, M. B.: Impacts of sodium chloride on the microbiota of a small river, Environ. Pollut., 17, 109-126, doi:10.1016/0013-9327(78)90044-7, 1978.

Dunson, W. A.: Tolerance to high temperature and salinity by tadpoles of the Philippine frog Rana cancrivora, Copeia, 375-378, 1977.

Furnus, G. N. A., Caffetti, J. D., García, E. M., Benítez, M. F., Pastori, M. C., and Fenocchio, A. S.: Baseline micronuclei and nuclear abnormalities frequencies in native fishes from the Paraná River (Argentina), Braz. J. Biol., 74, 217-221, doi:10.1590/1519-6984.13712, 2014.

Gomez-Meste, I., Tejedo, M., Ramayo, E., and Estepa, J.: Developmental alterations and osmoregulatory physiology of a larval anuran under osmotic stress, Physiol. Biochem. Zool., 77, $267-$ 274, doi:10.1086/378143, 2004.

Gutiérrez, J. S., Masero, J. A., Abad-Gómez, J. M., Villegas, A., and Sánchez-Guzmán, J. M.: Understanding the energetic costs of living in saline environments: effects of salinity on basal metabolic rate, body mass and daily energy consumption of a long-distance migratory shorebird, J. Exp. Biol., 214, 829-835, doi:10.1242/jeb.048223, 2011.

Hayretdağ, S., Gürkan, M., Yakin, B. Y., and Tok, C. V.: A preliminary study on micronuclei and nuclear abnormalities in the erythrocytes of some Colubrid snakes from Turkey, Biharean Biol., $8,53-55,2014$.
Howard, K. W. F. and Haynes, J.: Groundwater contamination due to road de-icing chemicals - salt balance implications, Geosci Can., 20, 1-8, 1993.

Jiraungkoorskul, W., Sahaphong, S., Kosai, P., and Kim, M.-H.: Micronucleus test: the effect of ascorbic acid on cadmium exposure in fish (Puntius altus), Res. J. Environ. Toxicol., 1, 27-36, doi:10.3923/rjet.2007.27.36, 2007.

Karraker, N.: Are embryonic and larval green frogs (Rana clamitans) insensitive to road deicing salt?, Herpetol. Conserv. Biol., 2, 35-41, 2007.

Kjensmo, J.: The influence of road salts on the salinity and the meromictic stability of Lake Svinsjoen, southeastern Norway, Hydrobiologia, 347, 151-158, 1997.

Madden, J. L, Drakos, S. G., Stehlik, J., McKellar, S. H., Rondina, M. T., Weyrich, A. S., and Selzman, C. H.: Baseline red blood cell osmotic fragility does not predict the degree of post-LVAD hemolysis, ASAIO J., 60, 524-528, doi:10.1097/MAT.0000000000000106, 2014.

Martem'yanov, V. I.: Salinity effect on freshwater fish, Zool. Zh., 68, 72-81, 1989.

Natchev, N., Tzankov, N., and Gemel, R.: Green frog invasion in the Black Sea: habitat ecology of the Pelophylax esculentus complex (Anura, Amphibia) population in the region of Shablenska Òzla lagoon in Bulgaria, Herpetol. Not., 4, 347-351, 2011.

Naumov, B., Tzankov, N., Popgeorgiev, G., Stojanov, A., and Kornilev, Y.: The dice snake (Natrix tessellata) in Bulgaria: distribution and morphology, Mertensiella, 18, 288-297, 2011.

Neill, W. T.: The occurrence of amphibians and reptiles in salt-water areas and a bibliography, B. Marine Sci. Gulf Carib., 8, 1-97, 1958.

Ortiz-Santaliestra, M. E., Fernández-Benéitez, M. J., Marco, A., and Lizana, M.: Influence of ammonium nitrate on larval antipredatory responses of two amphibians, Aquatic Toxicol., 99, 198-204, doi:10.1016/j.aquatox.2010.04.020, 2010.

Pastor, M. M., Proft, M., and Pascual-Ahuir, A.: Mitochondrial function is an inducible determinant of osmotic stress adaptation in yeast, J. Biol. Chem., 284, 30307-30317, doi:10.1074/jbc.M109.050682, 2009.

Shoemaker, V. H., Hillman, S. S., Hillyard, S. D., Jackson, D. C., McClanhan, L. L., Withers, P. C., and Wygoda, M. L.: Exchange of water, ions, and respiratory gases in terrestrial amphibians, in: Environmental physiology of the amphibians, edited by: Feder, M. E. and Burggren, W. W., The University of Chicago Press, 125-150, 1992.

Sillero, N. and Ribeiro, R.: Reproduction of Pelophylax perezi in brackish water in Porto (Portugal), Herpetol. Not., 3, 337-340, 2010.

Spotila, J. R. and Berman, E. N.: Determination of skin resistance and the role of the skin in controlling water loss in amphibians and reptiles, Comp. Biochem. Physiol. A, 55, 407-411, doi:10.1016/0300-9629(76)90069-4, 1976.

Stacy, N. I. Alleman, A. R., and Sayler, K. A.: Diagnostic hematology of reptiles, Clin. Lab. Med., 31, 87-108, doi:10.1016/j.cll.2010.10.006, 2011.

StatSoft, Inc.: STATISTICA (data analysis software system), version 7.0, www.statsoft.com, 2004. 
Stojanov, A., Tzankov, N., and Naumov, B.: Die Amphibien und Reptilien Bulgariens, Edition Chimaira, Frankfurt am Main, Germany, 2011.

Strunjak-Perovic, I., Lisicic, D., Coz-Rakovac, R., Popovic, N. T., Jadan, M., Benkovic, V., and Tadic, Z.: Evaluation of micronucleus and erythrocytic nuclear abnormalities in Balkan whip snake Hierophis gemonensis, Ecotoxicology, 19, 1460-1465, doi:10.1007/s10646-010-0531-y, 2010.
Walia, G. K., Handa, D., Kaur, H., and Kalotra, R.: Erythrocyte abnormalities in a freshwater fish, Labeo rohita exposed to tannery industry effluent, IJPBS, 3, 287-295, 2013.

Williams, D. D., Williams, N. E., and Cao, Y.: Road salt contamination of groundwater in a major metropolitan area and development of a biological index to monitor its impact, Water Res., 34, 127-138, doi:10.1016/S0043-1354(99)00129-3, 2000. 